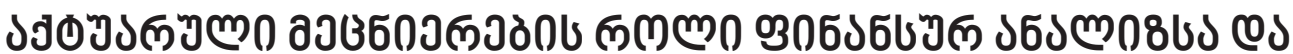

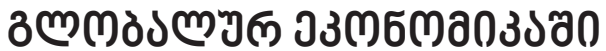

\section{БЈธง วอธกัdอ}

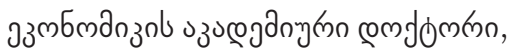

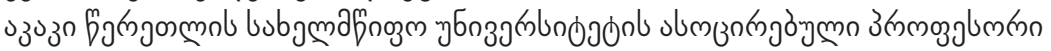

https://doi.org/10.35945/gb.2017.04.003

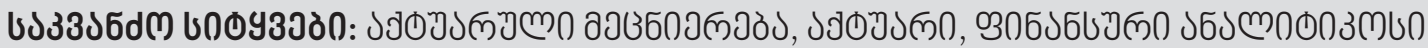

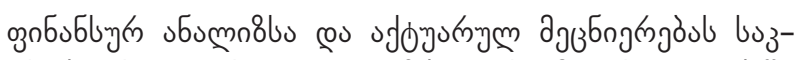

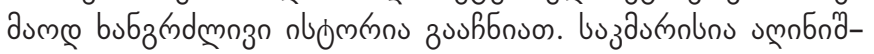

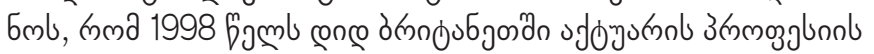

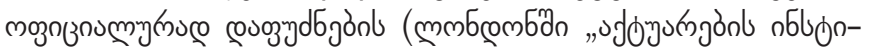

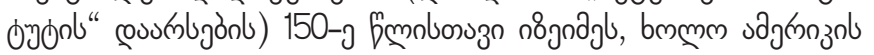

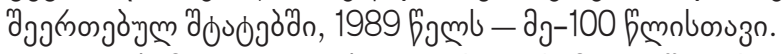

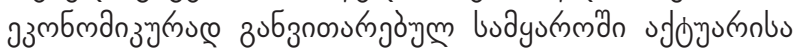

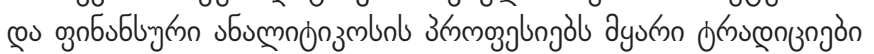

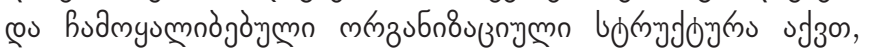

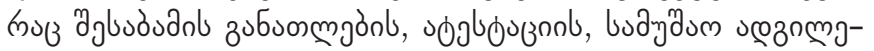

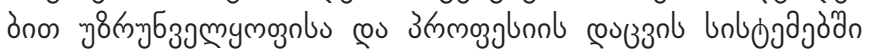

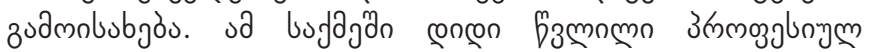

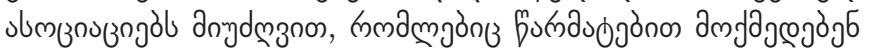

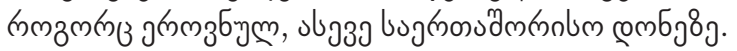

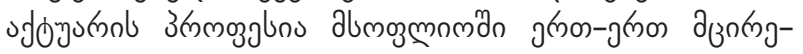

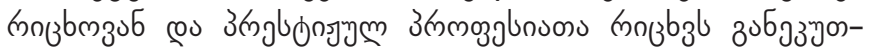

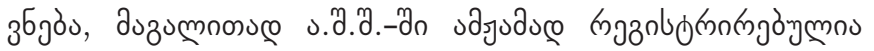

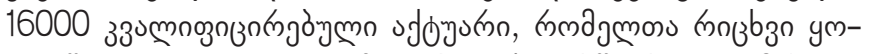

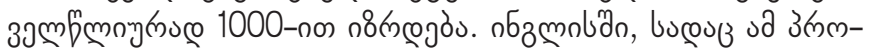

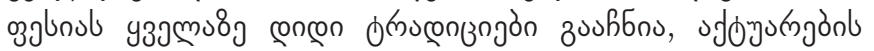

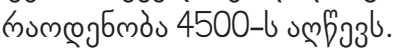

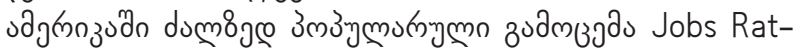

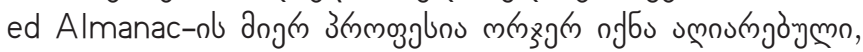

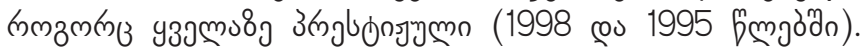

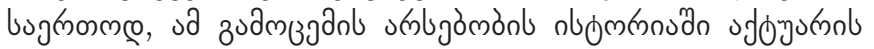

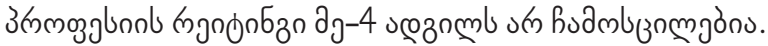

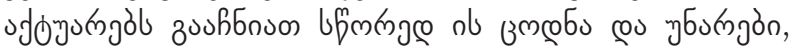

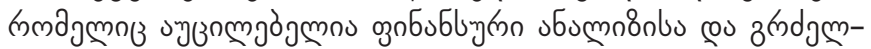

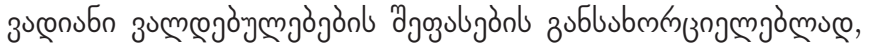

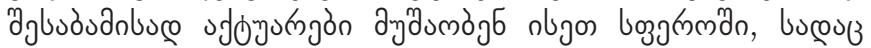

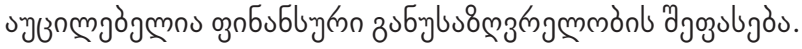

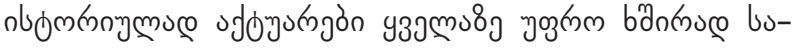

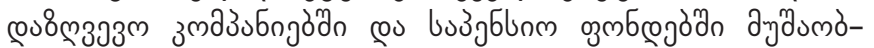

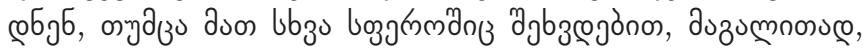

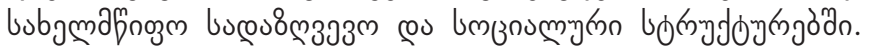

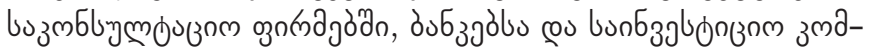

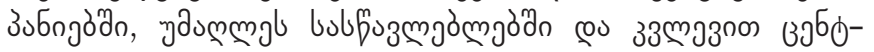

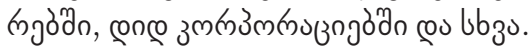

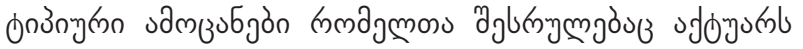

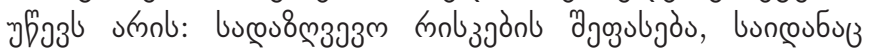

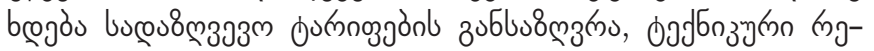
8g

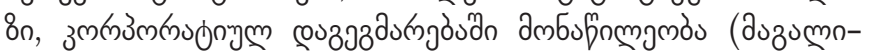

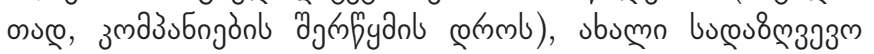

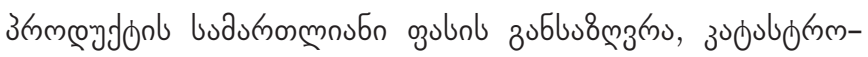

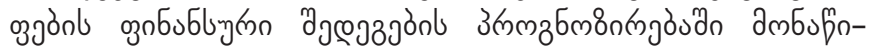

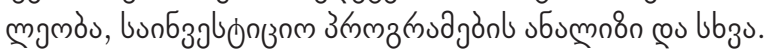

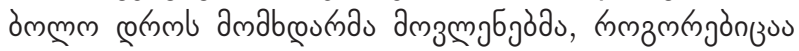

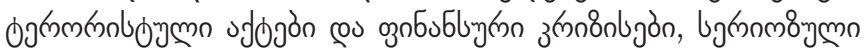

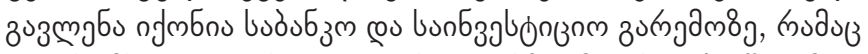

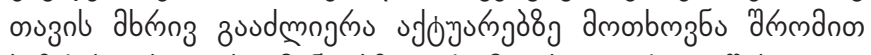

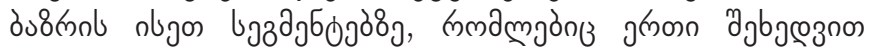

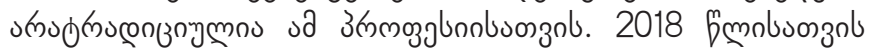

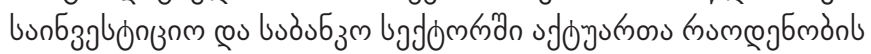

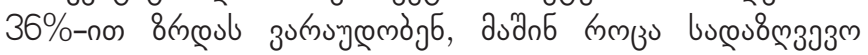
bədom

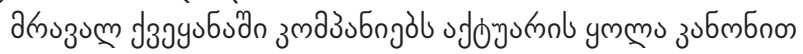

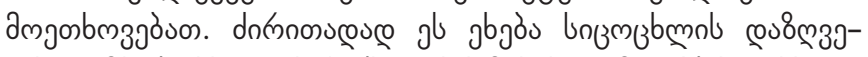

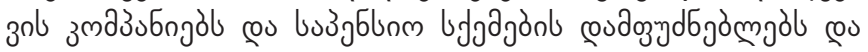

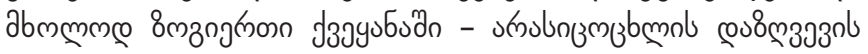
змд3งбnjall.

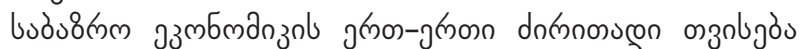

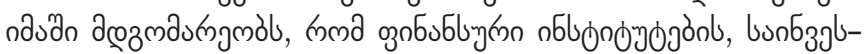

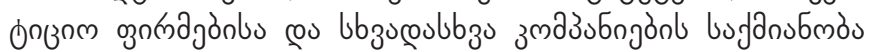

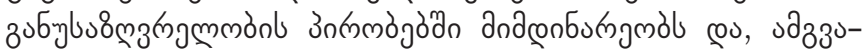

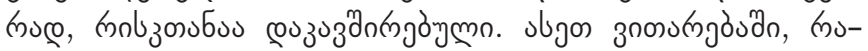

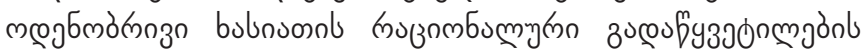

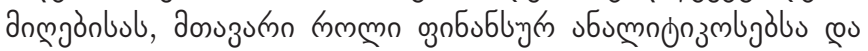
udoyutrgal jengagoson.

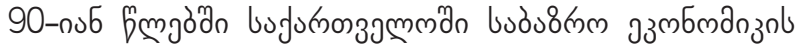

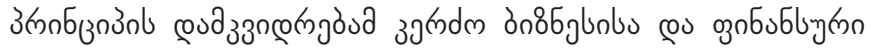

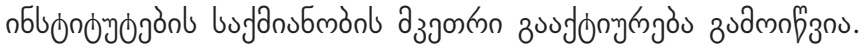

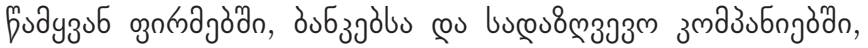

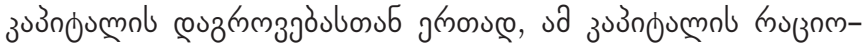

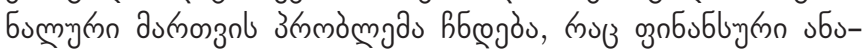

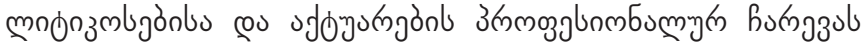
amnosbmal.

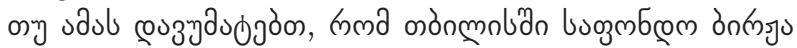

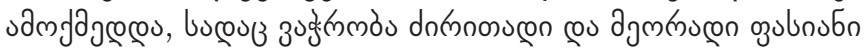

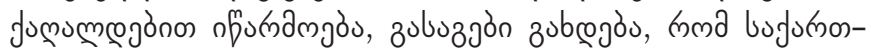

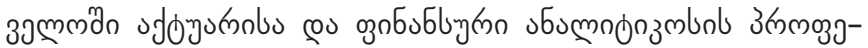

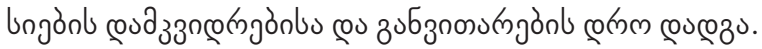

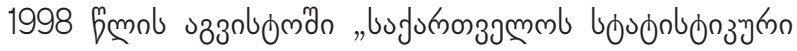

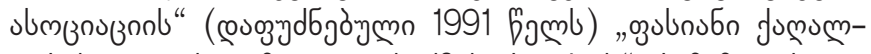

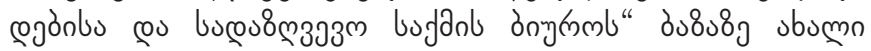
s mubuansuz

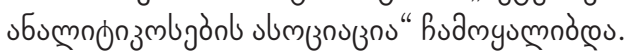

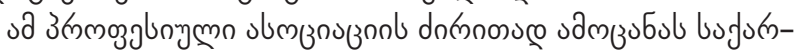




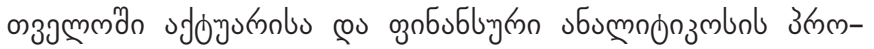

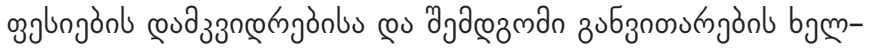

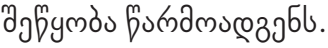

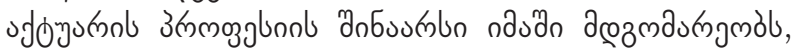

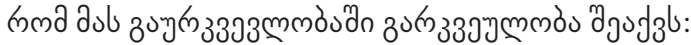

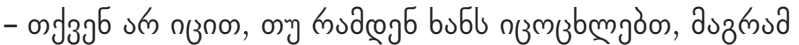

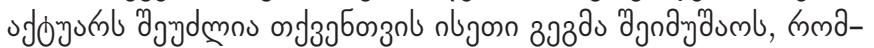

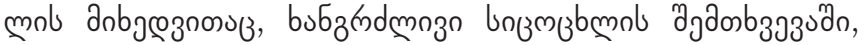

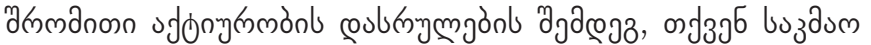

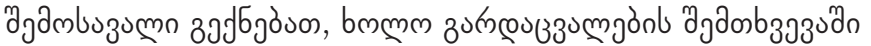

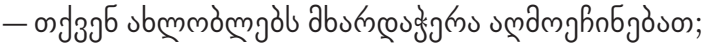

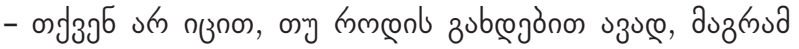

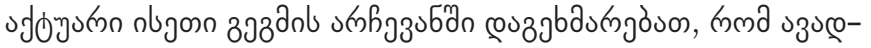

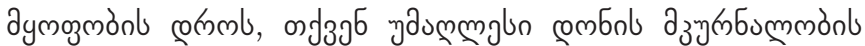

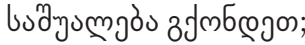

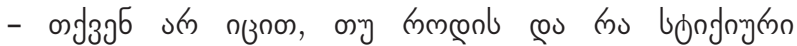

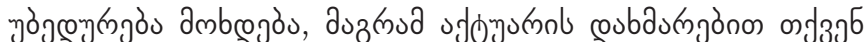

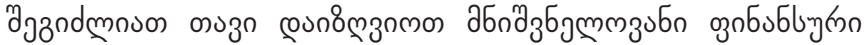

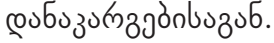

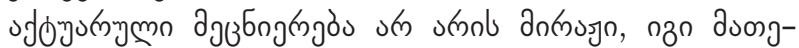

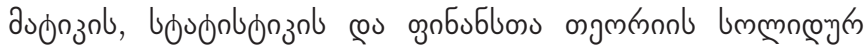

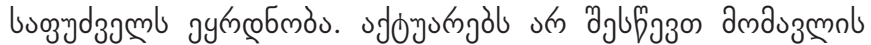

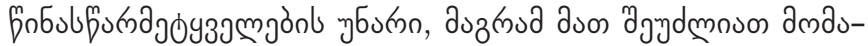

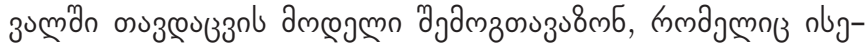

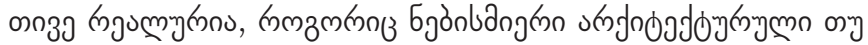

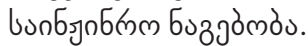

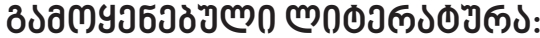

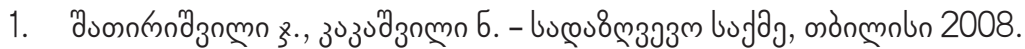

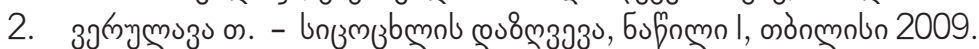

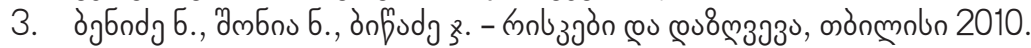

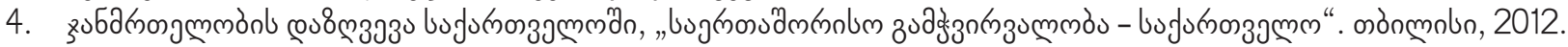




\section{ACTUARIAL SCIENCE AND THE ROLE OF FINANCIAL ANALYSIS IN THE GLOBAL ECONOMY}

NANA BENIDZE

https://doi.org/10.35945/gb.2017.04.003

$\mathrm{PhD}$ in Economics,

Asociated Professor of Akaki Tsereteli State University, Georgia

KEYWORDS: ACTUAL SCIENCE, ACTOR, FINANCIAL ANALYST

\section{SUMMARY}

Actuarial profession is one of the few small and prestigious occupations in the world. That's actuaries have the knowledge and skills that are necessary for financial analysis and assessment of long-term liabilities. Accordingly, actors work in a field where it is necessary to assess financial uncertainty.

The typical tasks to which the actors perform are: Assessment of insurance risks from which the insurance tariffs are determined; Calculation of Technical Reserves; Statistical analysis of claims; Participation in corporate planning (for instance when companies are merging); Determine the fair price of a new insurance product; Participation in predicting the financial results of disasters; Investment programs analysis and more. 